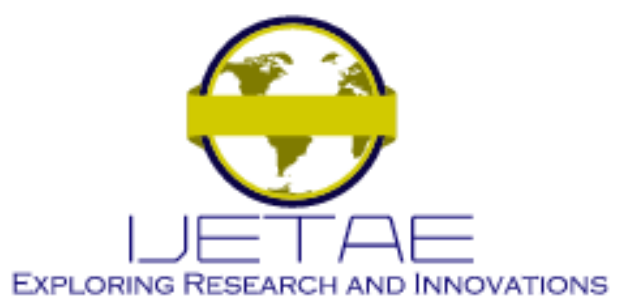

International Journal of Emerging Technology and Advanced Engineering

Website: www.ijetae.com (E-ISSN 2250-2459, Scopus Indexed, ISO 9001:2008 Certified Journal, Volume 11, Issue 10, October 2021)

Manuscript Received: 06 September 2021, Received in Revised form: 10 October 2021, Accepted: 15 October 2021

DOI: 10.46338/ijetae1021_03

\title{
Comparative Analysis of CNTFET Models through the Design of a Differential Amplifier
}

\author{
Gennaro Gelao ${ }^{1}$, Roberto Marani ${ }^{2}$, Anna Gina Perri ${ }^{3}$ \\ ${ }^{1,3}$ Electronic Devices Laboratory, Department of Electrical and Information Engineering, Polytechnic University of Bari, via E. \\ Orabona 4, 70125 Bari, Italy \\ ${ }^{2}$ National Research Council of Italy (CNR), Institute of Intelligent Industrial Technologies and Systems for Advanced \\ Manufacturing (STIIMA), Bari, via Amendola 122 D/O, 70126 Bari, Italy
}

\begin{abstract}
In this paper we compare simulation results on a differential pair circuit using a CNTFET model, already proposed by us, with the result obtained using Stanford model. We study the case of differential pair with differential input and single ended output as core of a $50 \mathrm{GHz}$ amplifier for $\mathrm{mm}$ waves band. We consider the case of a CNTFET having a single CNT tube with indices $(19,0)$ and $25 \mathrm{~nm}$ long. For this circuit we present result for its main parameters: gain, input impedance, output impedance, noise and distortion. Since the Stanford model includes fixed capacitance, for comparison we applied the same capacitance on our model. Since this capacitances dominate the high frequency cut, results are not much different, except for the lack of noise modelling in the Stanford model.
\end{abstract}

Keywords - Nanodevices, CNTFET, Modelling, mm-wave, THz, Noise, Differential Amplifier, Advanced Design System (ADS).

\section{INTRODUCTION}

The device modelling is an important tool in the development of new technologies and for application of mature technologies.

CNTFET is a new kind of molecular device, using a carbon nanotube as channel [1-7].

For conventional CNTFET (also denoted as C-CNTFET) [8-9], we have already proposed a compact, semi-empirical model [3-10], in which we introduced some improvements to allow an easy implementation both in SPICE and in Verilog-A, to carry out static and dynamic analysis of A/D circuits [12-18].

In this paper we present a comparison between our model and the Stanford one [19-20] through the design of a differential amplifier. for application between $50 \mathrm{GHz}$ and $500 \mathrm{GHz}$.
The simulation results, obtained using the software Advanced Design System (ADS), allow to show the differences between the considered models and the advantages of our model for the design of analogue VLSI circuits based on CNTFETs.

\section{A REVIEw Of Two CNTFET Models CONSIDERED}

\section{A. Our model}

An exhaustive description of our I-V CNTFET model is in [14-18] and therefore we suggest the reader to consult them.

In this Section we describe the main equations on which is based our CNTFET model.

When a positive voltage is applied between drain-source $\left(\mathrm{V}_{\mathrm{DS}}>0 \mathrm{~V}\right)$, the hypothesis of ballistic transport allows to assert that the current is constant along the CNT and therefore it can be calculated at the beginning of the channel, near the source, at the maximum of conduction band, where electrons from the source take up energy levels related to states with positive wave number, while the electrons from the drain take up energy levels related to states with negative wave number.

When a positive voltage is applied between gate-source $\left(\mathrm{V}_{\mathrm{GS}}>0 \mathrm{~V}\right)$, the conduction band at the channel beginning decreases by $\mathrm{qV}_{\mathrm{CNT}}$, where $\mathrm{V}_{\mathrm{CNT}}$ is the surface potential and $\mathrm{q}$ is the electron charge. With the hypothesis that each sub-band decreases by the same quantity along the whole channel length, the drain current for every single sub-band can be calculated using the Landauer formula [21]:

$$
\mathrm{I}_{\mathrm{DSp}}=\frac{4 \mathrm{qkT}}{\mathrm{h}}\left[\ln \left(1+\exp \xi_{\mathrm{Sp}}\right)-\ln \left(1+\exp \xi_{\mathrm{Dp}}\right)\right]
$$




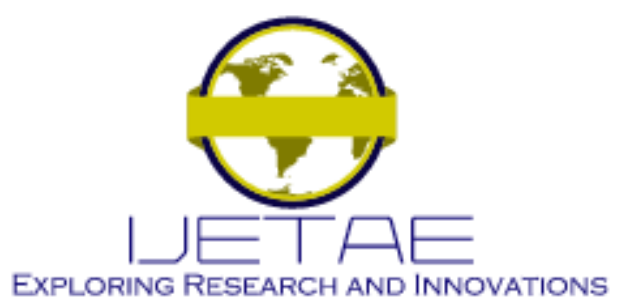

International Journal of Emerging Technology and Advanced Engineering

Website: www.ijetae.com (E-ISSN 2250-2459, Scopus Indexed, ISO 9001:2008 Certified Journal, Volume 11, Issue 10, October 2021)

Where $\mathrm{k}$ is the Boltzmann constant, $\mathrm{T}$ is the absolute temperature, $\mathrm{h}$ is the Planck constant, $\mathrm{p}$ is the number of sub-bands, while $\xi_{\mathrm{Sp}}$ and $\xi_{\mathrm{Dp}}$ have the following expressions:

$$
\xi_{\mathrm{Sp}}=\frac{\mathrm{qV}_{\mathrm{CNT}}-\mathrm{E}_{\mathrm{Cp}}}{\mathrm{kT}} \quad \text { and } \quad \xi_{\mathrm{Dp}}=\frac{\mathrm{qV}_{\mathrm{CNT}}-\mathrm{E}_{\mathrm{Cp}}-\mathrm{qV}_{\mathrm{DS}}}{\mathrm{kT}}
$$

being $E_{C p}$ the sub-bands conduction minima.

Therefore the total drain current can be expressed as:

$\mathrm{I}_{\mathrm{DS}}=\frac{4 \mathrm{qkT}}{\mathrm{h}} \sum_{\mathrm{p}}\left[\ln \left(1+\exp \xi_{\mathrm{Sp}}\right)-\ln \left(1+\exp \xi_{\mathrm{Dp}}\right)\right]$

The surface potential, $\mathrm{V}_{\mathrm{CNT}}$, is evaluated by the following approximation:

$V_{C N T}= \begin{cases}V_{G S} & \text { for } V_{G S}<\frac{E_{C}}{q} \\ V_{G S}-\alpha\left(V_{G S}-\frac{E_{C}}{q}\right) & \text { for } V_{G S} \geq \frac{E_{C}}{q}\end{cases}$

Where $E_{C}$ is the conduction band minimum for the first sub-band and $\alpha$ is a parameter, depending on the $V_{D S}$ voltage, on CNTFET diameter and gate oxide capacitance, extracted from the experimental device characteristics [4-5].

\section{B. Stanford model}

The Stanford-Source Virtual Carbon Nanotube FieldEffect Transistor model (VS-CNFET) [19-20] is a semiempirical model that describes the current-voltage (I-V) and capacitance-voltage $(\mathrm{C}-\mathrm{V})$ characteristics in a shortchannel metal-oxide-semiconductor field-effect transistor (MOSFET) with carbon nanotubes as the channel material. The VS-CNFET model is based on the semi-empirical virtual source concept calibrated to experimental data.

In particular the intrinsic drain current and terminal charges are based on the virtual source (VS) model, with the virtual source velocity extracted from experimental data for different channel lengths (ranging from 3-um down to 15-nm).

Moreover the VS-CNFET model takes in account the following parasitic effects:

1. direct source-to-drain and band-to-band tunneling current calibrated by numerical simulations;
2. metal-to-CNT contact resistances calibrated by experimental data;

3. parasitic capacitance including gate-to-CNT fringe capacitances and gate-to-contact coupling capacitances.

The inputs to the VS-CNFET model are the physical device design including device dimensions, CNT diameter, gate oxide thickness, etc.

\section{DIFFERENTIAL AMPLIFIER}

For the comparison we use a basic differential pair circuit, presented in Fig. 1 with symmetric supplies, the positive $\mathrm{V}_{\mathrm{DD}}=2 \mathrm{~V}$ the negative $-\mathrm{V}_{\mathrm{DD}}=-2 \mathrm{~V}$ (named MinusVDD in Fig. 1.

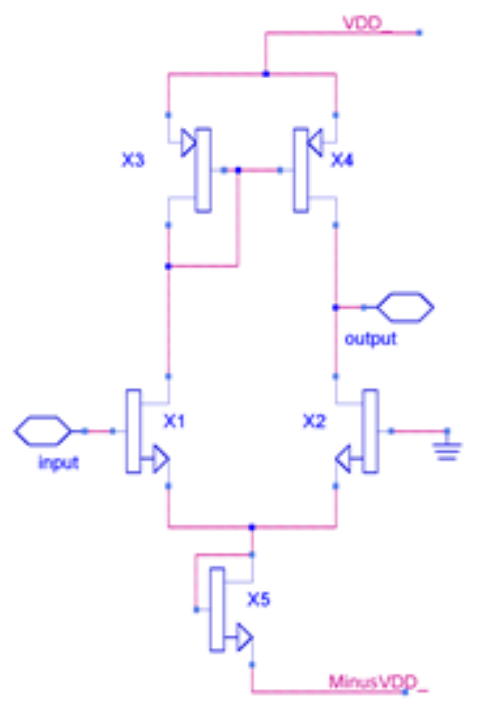

Figure 1. Differential circuit using CNTFET.

We use five CNTFET, X1 X2 X3 X4 X5, each made by a single carbon nanotube channel with indices $(19,0)$ and length $25 \mathrm{~nm}$. These values derive from a previous analysis [22], where we observed that short tubes gives the best performance at high frequency. In order to simulate the output load, both drain of the differential pair are directly coupled to gate input of a differential pair complementary to the one in Fig. 1, i.e. obtained swapping position of differential pair and a current generator, and swapping $\mathrm{N}$ devices with $\mathrm{P}$ devices.

We ignore the embedding parasitic element, since these would cut down the gain at higher frequencies and cover differences between models. 


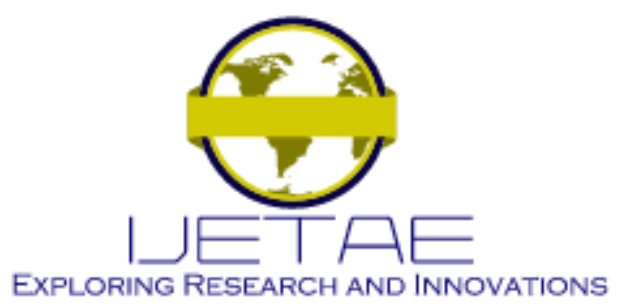

International Journal of Emerging Technology and Advanced Engineering

Website: www.ijetae.com (E-ISSN 2250-2459, Scopus Indexed, ISO 9001:2008 Certified Journal, Volume 11, Issue 10, October 2021)

As Stanford model includes voltage independent capacitances, presumably for terminal pads, we measured values of these capacitances from simulation of a bare CNTFET obtaining a $2.19 \mathrm{aF}$ capacitance between gate and source, and a $1.44 \mathrm{aF}$ capacitance between drain an source.

To make comparison more balanced we add two capacitor to our model with these values.

We consider first the polarizations: in Fig. 2 we show the drain current of the differential pair, our model foresees lower current, from $30 \%$ less at $\mathrm{V}_{\mathrm{DD}}=1 \mathrm{~V}$ to $15 \%$ less at

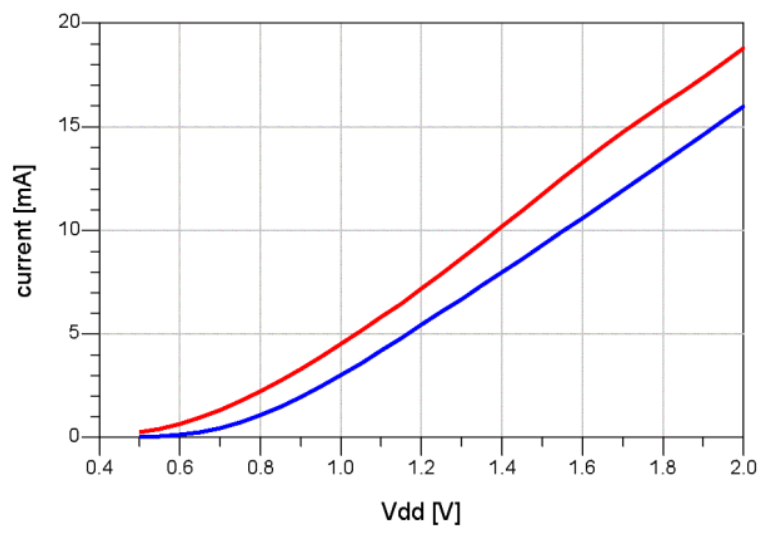

$\mathrm{V}_{\mathrm{DD}}=2 \mathrm{~V}$.

Figure 2. Drain current of differential pair of Fig. 1, for various supply voltages. The blue line represent our model results and the red line represent the Stanford model result.

$\mathrm{V}_{\mathrm{ds}}$ for the differential pair is lower, while the $\mathrm{V}_{\mathrm{ds}}$ of the current source is higher, the difference being about $0.1 \mathrm{~V}$.

In Fig. 3 the differential voltage gain of the proposed circuit at low frequencies, below $1 \mathrm{GHz}$, foreseen by our model is $21.2 \mathrm{~dB}$, while Stanford model is $0.7 \mathrm{~dB}$ lower.

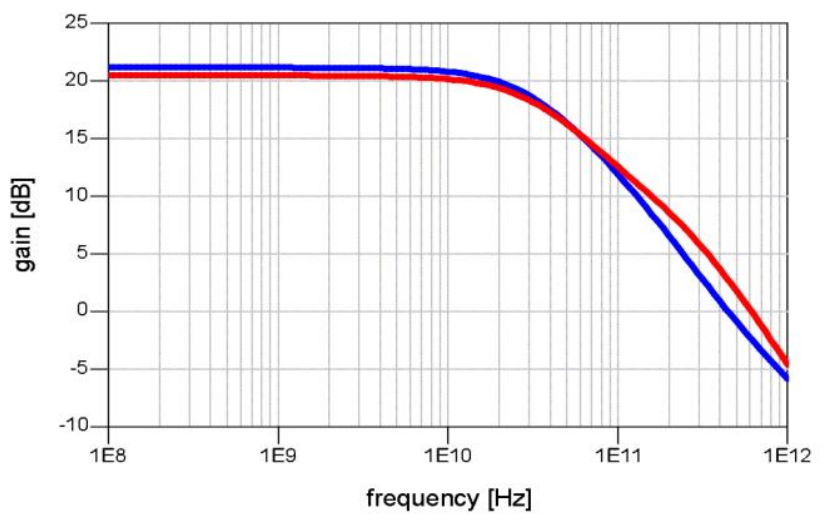

Figure 3. Differential gain. Colours as for Fig. 2.
For the $3 \mathrm{~dB}$ cut frequencies, values are $34 \mathrm{GHz}$ for our model and 12\% higher, $38 \mathrm{GHz}$, for Stanford model. On the tail of the curve, the $0 \mathrm{~dB}$ gain frequency is $0.44 \mathrm{THz}$ for our model and 36\% higher, $0.60 \mathrm{THz}$ for Stanford model.

In our model we implemented the noise generator according to the theory widely illustrated in [23], where we have proposed a compact noise model of CNTFET, and therefore we suggest the reader to consult this paper [23].

Fig. 4 shows the proposed CNTFET noise model, including five different noise sources.

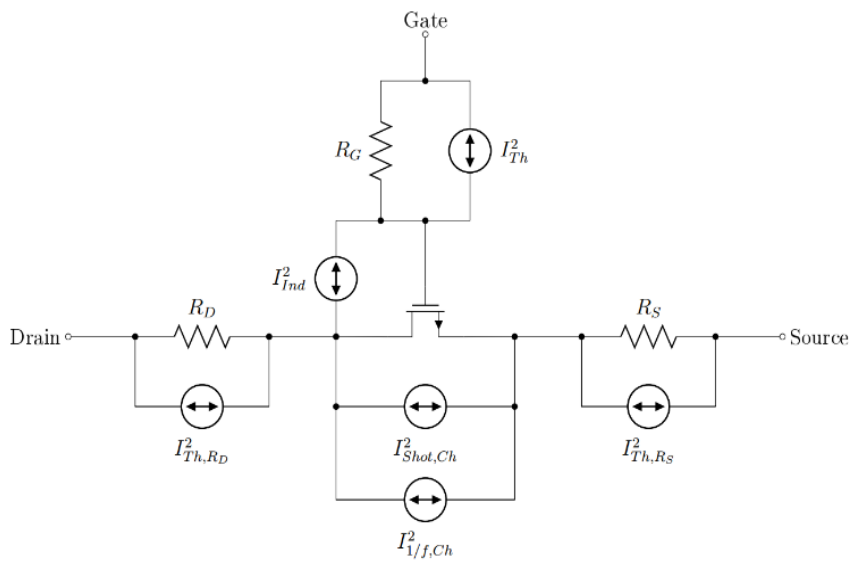

Figure 4. The proposed CNTFET noise model, including the main noise sources method [23].

In particular we have considered the main noise sources, which are:

1. Thermal noise of $R_{G}$

2. Thermal noise of $R_{S}$ and $R_{D}$

3. Channel thermal noise and shot noise

4. Flicker noise

5. Channel-induced gate noise.

In Fig. 5 we present the results for output noise obtained by circuit noise simulation.

As you can see, we obtain a minimum noise voltage rms value $78 \mathrm{nV} / \mathrm{Hz}^{1 / 2}$ for $34 \mathrm{GHz}$, and values below 0.25 $\mu \mathrm{V} / \mathrm{Hz}^{1 / 2}$ between $1 \mathrm{GHz}$ and $125 \mathrm{GHz}$. 


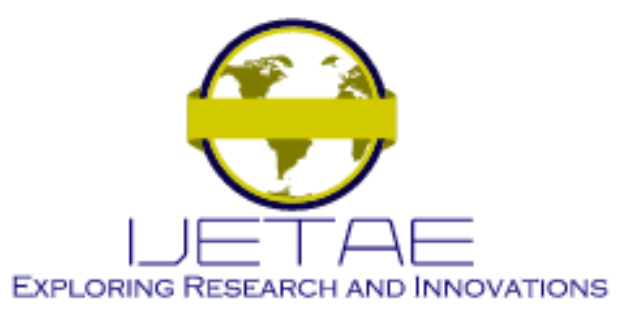

International Journal of Emerging Technology and Advanced Engineering

Website: www.ijetae.com (E-ISSN 2250-2459, Scopus Indexed, ISO 9001:2008 Certified Journal, Volume 11, Issue 10, October 2021)

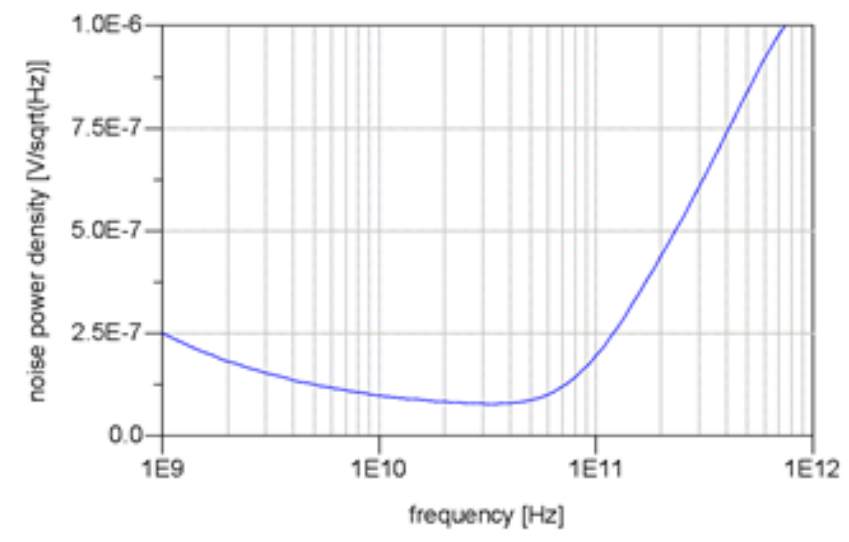

Figure 5. Noise spectral power density at output of circuit of Fig. 1.

In this paper the analysis is done without considering embedding parasitic effects. We present the idealized circuit without parasitics [22], since parasitics depend on technology. Any limit presented including parasitics is strongly dependent to the chosen technology, which is exactly what we want to avoid when we look for an intrinsic limit of the device.

In the case the analysis must to estimate parasitic elements in CNTs embedded Integrated Circuits, it will be necessary to apply the same procedure already proposed by us in [24-25].

We have not a comparison for the noise performance of the circuit because the Stanford model does not simulate noise, and, according our opinion, this is a limitation of this model when CNTFETs is used in the design of $\mathrm{mm}$ band (sub-THz) transmission systems, currently under strong development [26].

\section{Transient Analysis Of The Proposed Circuit}

In Fig. 6 we shows the transient analysis for an input differential sine of $\mathrm{V}_{\text {in }}= \pm 1 \mathrm{mV}$ amplitude at $50 \mathrm{GHz}$, at a frequency above the $3 \mathrm{~dB}$ cut frequency since linear simulation foresee $6.57(16 \mathrm{~dB})$ voltage gain.

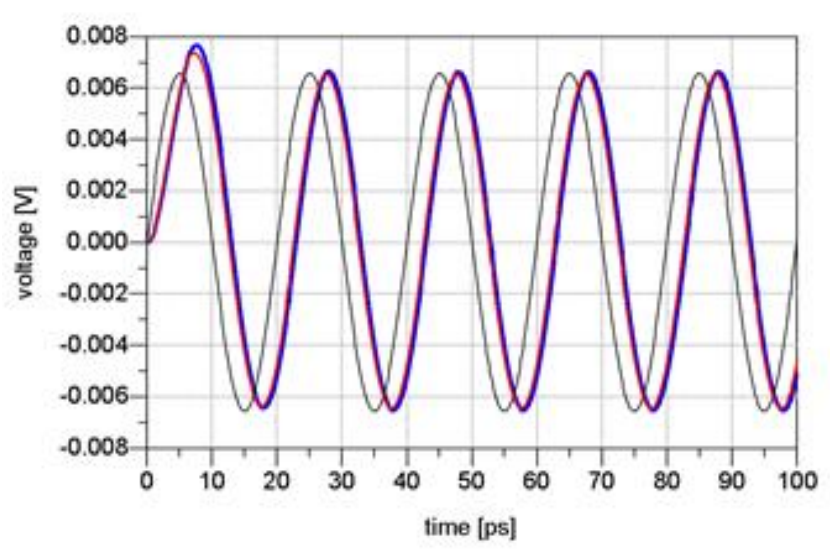

Figure 6. Transient output for sinusoidal input. The input differential signal is in black, the output is in blue for our model and in red for Stanford model. Input has been multiplied by the gain obtained from linear analysis using our model. Continuous components have been subtracted.

Transient simulation shows a small transient in the form of decreasing exponential, which appears as a slow derive of the mean voltage of the signal, its voltage values at first peak of sinusoid is $1.0 \mathrm{mV}$ for our model and $0.8 \mathrm{mV}$ for Stanford one. Distortion is not negligible and not visible in Fig. 6 since input signal amplitude is small compared to the harmonic intercept value, that we will show later.

We present in Fig. 7 the differential input admittance, while in Fig. 8 the output single ended impedance.

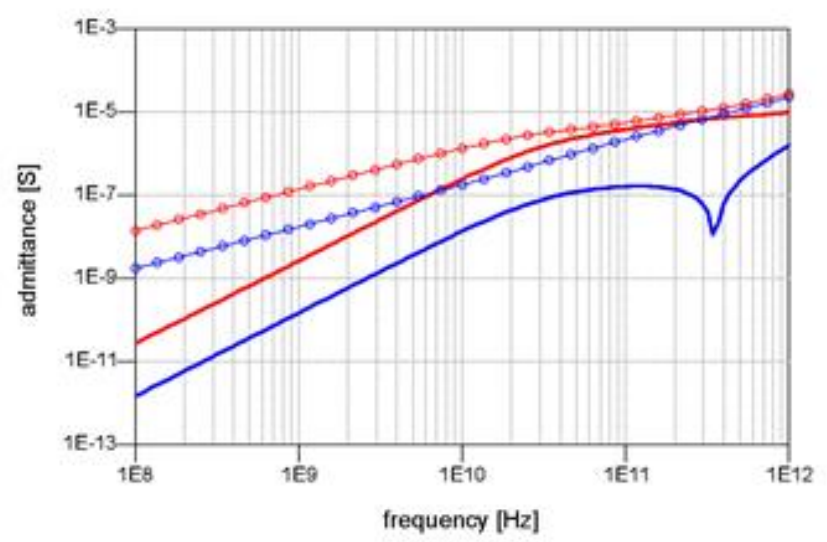

Figure 7. Differential input admittance, continuous line are real part, while imaginary parts is represented with a line plus circles. Colours as for Fig. 2. 


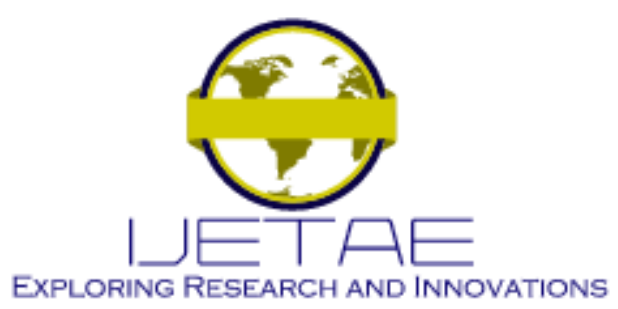

International Journal of Emerging Technology and Advanced Engineering

Website: www.ijetae.com (E-ISSN 2250-2459, Scopus Indexed, ISO 9001:2008 Certified Journal, Volume 11, Issue 10, October 2021)

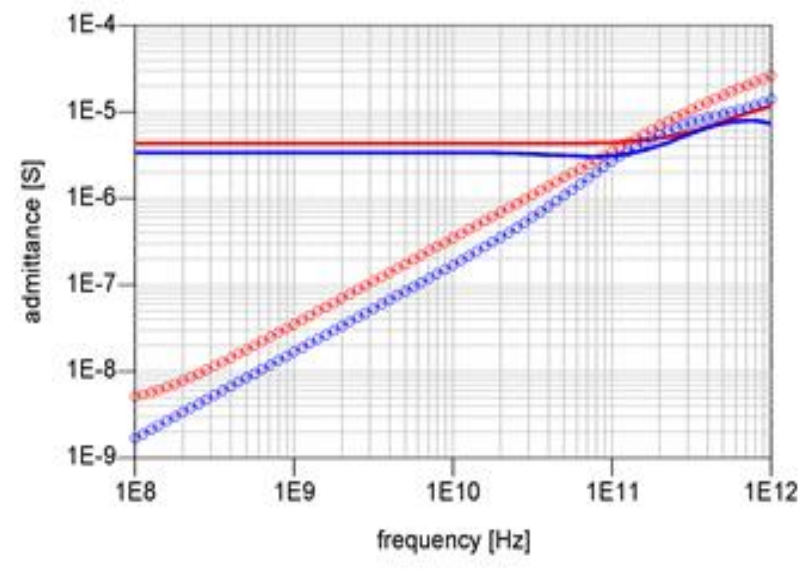

Figure 8. Output impedance, continuous line are for the real part, circles for imaginary part. Colours as for Fig. 2.

The input differential admittance is dominated by a capacitance component, our model foresees a value 8 times smaller than the values from Stanford model for frequencies below $100 \mathrm{GHz}$

For the output impedance, the resistive component is dominant at frequencies below $100 \mathrm{GHz}$, above this frequency the capacitive component became dominant. For frequencies below $100 \mathrm{GHz}$ our model foresee $20 \%$ lower real part and $50 \%$ lower capacitive part, above this frequency, our model still gives lower result but relative differences depends on frequency.

\section{HARMONIC DISTORTION}

We ran a transient simulation with a differential input signal at $50 \mathrm{GHz}$. We measured the simulated output harmonic component for various periods until we see transient effects disappear. Since transient effect are detectable till the $5^{\text {th }}$ period, we selected the $40^{\text {th }}$ period to measure the harmonic components from $2^{\text {nd }}$ to the $5^{\text {th }}$.

In Table I we list the ratios of higher harmonic to the first harmonic.
TABLE I

RATIO OF THE HIGHER HARMONIC TO THE FUNDAMENTAL COMPONENT AT $50 \mathrm{GHZ}$. UNREPORTED VALUES ARE COVERED BY NUMERICAL NOISE.

\begin{tabular}{|l|l|l|l|l|l|l|l|l|}
\hline$V_{\text {in }}$ & \multicolumn{6}{|c|}{ Harmonics (our model) } & \multicolumn{5}{c|}{$\begin{array}{c}\text { Harmonics (Stanford } \\
\text { model) }\end{array}$} \\
\hline [V] & 2nd & 3rd & 4th & 5th & 2nd & 3rd & 4th & 5th \\
\hline $10^{-3}$ & 1.38 & 1.15 & 5.40 & 2.00 & 9.31 & 4.49 & 3.05 & 1.90 \\
& $10^{-2}$ & $10^{-3}$ & $10^{-5}$ & $10^{-6}$ & $10^{-3}$ & $10^{-4}$ & $10^{-5}$ & $10^{-6}$ \\
\hline $10^{-4}$ & 1.38 & 1.15 & 5.40 & 2.66 & 9.22 & 4.41 & 2.97 & 1.85 \\
& $10^{-3}$ & $10^{-5}$ & $10^{-8}$ & $10^{-10}$ & $10^{-4}$ & $10^{-4}$ & $10^{-8}$ & $10^{-10}$ \\
\hline $10^{-5}$ & 1.38 & - & - & - & 9.22 & 4.41 & 3.00 & - \\
& $10^{-4}$ & & & & $10^{-5}$ & $10^{-4}$ & $10^{-11}$ & \\
\hline $10^{-6}$ & 1.38 & - & - & - & 9.21 & - & - & - \\
& $10^{-5}$ & & & & $10^{-6}$ & & & \\
\hline
\end{tabular}

The values for the $\mathrm{k}$-th harmonic distortion relative to the first harmonic could be easily approximated with the function $\left(\mathrm{V}_{\mathrm{in}} / \mathrm{V}_{\mathrm{k}}\right)^{\mathrm{k}-1}$ from which we could obtain the values of the intercept $\mathrm{V}_{\mathrm{k}}$, that we present in Table II.

TABLE II

INTERCEPT POINT FOR HARMONIC COMPONENTS AT 50 GHZ OBTAINED BY TABLE I.

\begin{tabular}{|l|l|l|l|l|l|l|l|l|}
\hline \multirow{2}{*}{$\mathbf{V}_{\text {in }}$} & \multicolumn{5}{|c|}{$\begin{array}{c}\text { Harmonics intercept (our } \\
\text { model) }\end{array}$} & \multicolumn{5}{c|}{ Harmonics intercept (Stanford } \\
model)
\end{tabular}

We observe that obtained values for $\mathrm{V}_{\mathrm{k}}$ are almost independent from $V_{\text {in }}$ as it should be.

As further check, in Fig. 9 we report the harmonic distortions measured by simulation using our model and the approximating functions $\left(\mathrm{V}_{\text {in }} / \mathrm{V}_{\mathrm{k}}\right)^{\mathrm{k}-1}$ using the value of $\mathrm{V}_{\mathrm{k}}$ from Table II for $\mathrm{V}_{\mathrm{in}}=1 \mathrm{mV}$. 


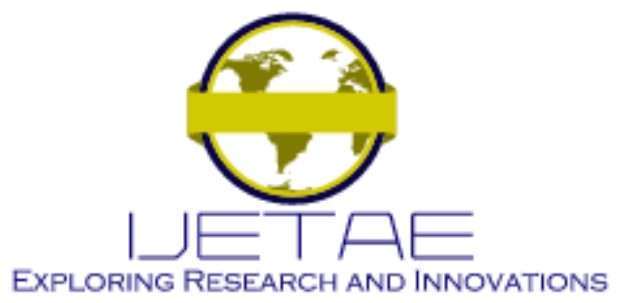

International Journal of Emerging Technology and Advanced Engineering

Website: www.ijetae.com (E-ISSN 2250-2459, Scopus Indexed, ISO 9001:2008 Certified Journal, Volume 11, Issue 10, October 2021)

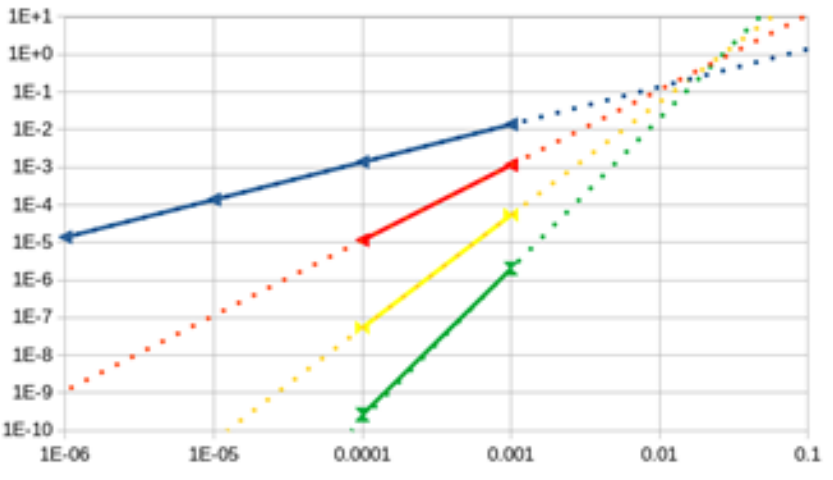

Figure 9. Harmonic distortion components relative to the first harmonic vs input voltage for our model. Distortions from simulations are represented by markers connected by a continuous line, while approximating functions are presented as dashed lines with the same colour sequence. The $2^{\text {nd }}$, the $3^{\text {rd }}$, the $4^{\text {th }}$ and the $5^{\text {th }}$ relative component are respectively in blue, red, yellow and green.

We see that the functions fit not only the $1 \mathrm{mV}$ values but fit all the data.

Since we have to seek for the lowest $\mathrm{V}_{\mathrm{k}}$ value, from table 2 we obtain an intercept at $25 \mathrm{mV}$ for our model, and at $27 \mathrm{mV}$ for Stanford model, in both cases due to the 5 th harmonic.

If we use Table I to compare distortion values, we observe that the worst case is the $3^{\text {rd }}$ harmonic distortion for which our model foresee a distortion 2.30 times that foreseen by Stanford model. For the other harmonics the difference is smaller but our model still predicts larger distortions.

We stress that none of the examined model consider self-heating due to power dissipation.

\section{CONCLUSion AND Future DEVElopMENTS}

We have compared the simulation results for a differential amplifier using our model for CNTFET to the simulation result of Stanford model.

The values of gain at various frequencies are comparable, with comparable results for characteristic frequency point at $-3 \mathrm{~dB}$ and at gain $=1$.

The largest difference between the simulation results comes from the differential input admittance for which our model foresees a values 8 times smaller.
It has not been possible to compare noise simulations, since, while our model simulates noise, the Stanford model does not, and, according our opinion, this is a limitation of this model when CNTFETs is used in the design of $\mathrm{mm}$ band (sub-THz) transmission systems, currently under strong development.

For distortions, while our model predicts always higher values for harmonic distortions, we obtained similar results for the harmonic intercept since this value is due to the $5^{\text {th }}$ harmonic for which models predict similar results.

Currently we are studying in more detail the effect of temperature [27-29] and of noise [30] in other circuits based on CNTFETs.

\section{REFERENCES}

[1] Perri, A.G., and R. Marani, R. 2017. CNTFET Electronics: Design Principles. Ed. Progedit. Bari, Italy.

[2] Jafarbeglou, M., Abdouss, M., and Ramezanianpour, A.A. 2015. Nanoscience and Nano Engineering in Concrete Advances A Review. International Journal of Nanoscience and Nanotechnology, 11(4), 263-273.

[3] Marani, R., and Perri, A.G. 2009. CNTFET modelling for Electronic Circuit Design. ElectroChemical Transactions, 23(1), 429-437.

[4] Gelao, G., Marani, R., Diana, R., and Perri, A.G. 2011. A SemiEmpirical SPICE Model for n-type Conventional CNTFETs. IEEE Transactions on Nanotechnology, 10(3), 506-512.

[5] Marani, R., and Perri, A.G. 2011. A Compact, Semi-empirical Model of Carbon Nanotube Field Effect Transistors oriented to Simulation Software. Current Nanoscience, 7(2), 245-253.

[6] Marani, R., and Perri, A.G. 2012. A DC Model of Carbon Nanotube Field Effect Transistor for CAD Applications. International Journal of Electronics, 99(3), 427- 444.

[7] Marani, R., Gelao, G., and Perri, A.G. 2012. Comparison of ABM SPICE library with Verilog-A for Compact CNTFET model implementation. Current Nanoscience, 8(4), 556-565.

[8] Marani, R., Gelao, G., and Perri, A.G. 2013. Modelling of Carbon Nanotube Field Effect Transistors oriented to SPICE software for A/D circuit design. Microelectronics Journal, 44(1), 33-39.

[9] Marani, R., and Perri, A.G. 2016. Analysis of CNTFETs Operating in SubThreshold Region for Low Power Digital Applications. ECS Journal of Solid State Science and Technology, 5(2), M1-M4.

[10] Marani, R., and Perri, A.G. 2016.. A De-Embedding Procedure to Determine the Equivalent Circuit Parameters of RF CNTFETs, ECS Journal of Solid State Science and Technology, 5(5), M31-M34.

[11] Verilog-AMS language reference manual. 2014.Version 2.2.

[12] Marani, R., and Perri, A.G. 2016. A Simulation Study of Analogue and Logic Circuits with CNTFETs. ECS Journal of Solid State Science and Technology, 5(6), M38-M43. 


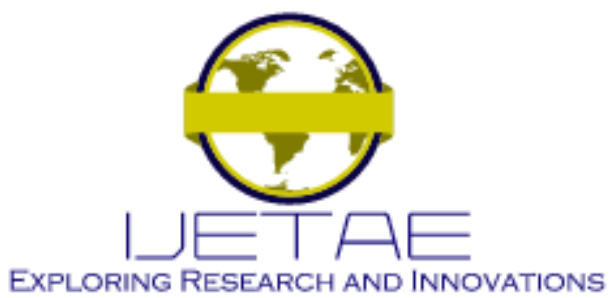

International Journal of Emerging Technology and Advanced Engineering

Website: www.ijetae.com (E-ISSN 2250-2459, Scopus Indexed, ISO 9001:2008 Certified Journal, Volume 11, Issue 10, October 2021)

[13] Marani, R., and Perri, A.G. 2016. A Comparison of CNTFET Models through the Design of a SRAM Cell. ECS Journal of Solid State Science and Technology, 5(10), M118-M126.

[14] Gelao, G., Marani, R., Pizzulli, L., and Perri, A.G. 2015. A Model to Improve Analysis of CNTFET Logic Gates in Verilog-A-Part I: Static Analysis. Current Nanoscience, 11(4), 515-526.

[15] Gelao, G., Marani, R., Pizzulli, L., and Perri, A.G. 2015. A Model to Improve Analysis of CNTFET Logic Gates in Verilog-A-Part II: Dynamic Analysis. Current Nanoscience, 11(6), 770-783.

[16] Marani, R., and Perri, A.G. 2018. Design and Simulation Study of Full Adder Circuit based on CNTFET and CMOS technology by ADS, ECS Journal of Solid State Science and Technology, 7(6), M108-M122.

[17] Marani, R., and Perri, A.G. 2020. Techniques to improve the Performance in the CNTFET-based Analogue Circuit Design. ECS Journal of Solid State Science and Technology, 9(3).

[18] Marani, R., and Perri, A.G. 2020. Impact of Technology on CNTFET-based Circuits Performance. ECS Journal of Solid State Science and Technology, 9(5).

[19] Lee, C-S., Pop, E., Franklin, A.D., Haensch, W. and Wong, H.-S. P. 2015. A Compact Virtual-Source Model for CarbonNanotube FETs in the Sub-10-nmRegime-Part I: Intrinsic Elements. IEEE Transactions on Electron Devices, 62(9), 3061-3069.

[20] Lee, C-S., Pop, E., Franklin, A.D., Haensch, W. and Wong, H.-S. P. 2015. A Compact Virtual-Source Model for Carbon Nanotube FieldEffect Transistors in the Sub-10-nm Regime-Part II: Extrinsic Elements, Performance Assessment, and Design Optimization. IEEE Transactions on Electron Devices, 62(9), 3070-3078.

[21] Datta, S. 1995. Cambridge Studies in Semiconductor Physics and Microelectronic Engineering 3. Electronic Transport in Mesoscopic Systems, New York: Cambridge University Press.
[22] Gelao, G., Marani, R., and Perri, A.G. 2021. Analysis of limits of CNTFET devices through the design of a differential amplifier. ECS Journal of Solid State Science and Technology, 10(6).

[23] Marani, R., Gelao, G., and Perri, A.G. 2017. A Compact Noise Model for C-CNTFETs. ECS Journal of Solid State Science and Technology, 6(4), M118-M126.

[24] Marani, R., and Perri, A.G. 2020. Effects of Parasitic Elements of Interconnection Lines in CNT Embedded Integrated Circuits. ECS Journal of Solid State Science and Technology, 9(2).

[25] Marani, R., and Perri, A.G. 2021. A Procedure to Analyse a CNTFET-based NOT Gate with Parasitic Elements of Interconnection Lines. International Journal of Nanoscience and Nanotechnology, 17(3), 161-171.

[26] Park, J., Kang, S. Thyagarajan, S. V., Alon, E. and Niknejad, A.M. 2012. A $260 \mathrm{GHz}$ fully integrated CMOS transceiver for wireless chip-to-chip communication. Proceedings of 2012 Symposium on VLSI Circuits (VLSIC), Honolulu, U.S.A, 48-49.

[27] Gelao, G., Marani, R., and Perri, A.G. 2018. Effects of Temperature in CNTFET-Based Design of Analog Circuits. ECS Journal of Solid State Science and Technology, 7(2), M16-M21.

[28] Gelao, G., Marani, R., and Perri, A.G. 2018. Effects of Temperature in CNTFET-Based Design of Digital Circuits. ECS Journal of Solid State Science and Technology, 7(3), M41-M48.

[29] Marani, R., and Perri, A.G. 2021. Temperature Dependence of I-V Characteristics in CNTFET Models: A Comparison. International Journal of Nanoscience and Nanotechnology, 17(1), 33-39.

[30] Marani, R., and Perri, A.G. 2021. A Simulation Study of Noise Behavior in Basic Current Mirror using CNTFET and MOSFET. International Journal of Emerging Technology and Advanced Engineering, 11(7), 13-18. 